Document downloaded from:

http://hdl.handle.net/10251/50669

This paper must be cited as:

Cembrero Cil, J.; Busquets Mataix, DJ.; Rayón Encinas, E.; Pascual Guillamón, M.; Pérez Puig, MA.; Marí Soucase, B. (2013). Control parameters on the fabrication of ZnO hollow nanocolumns. Materials Science in Semiconductor Processing. 16:211-216.

https://doi.org/10.1016/j.mssp.2012.04.014

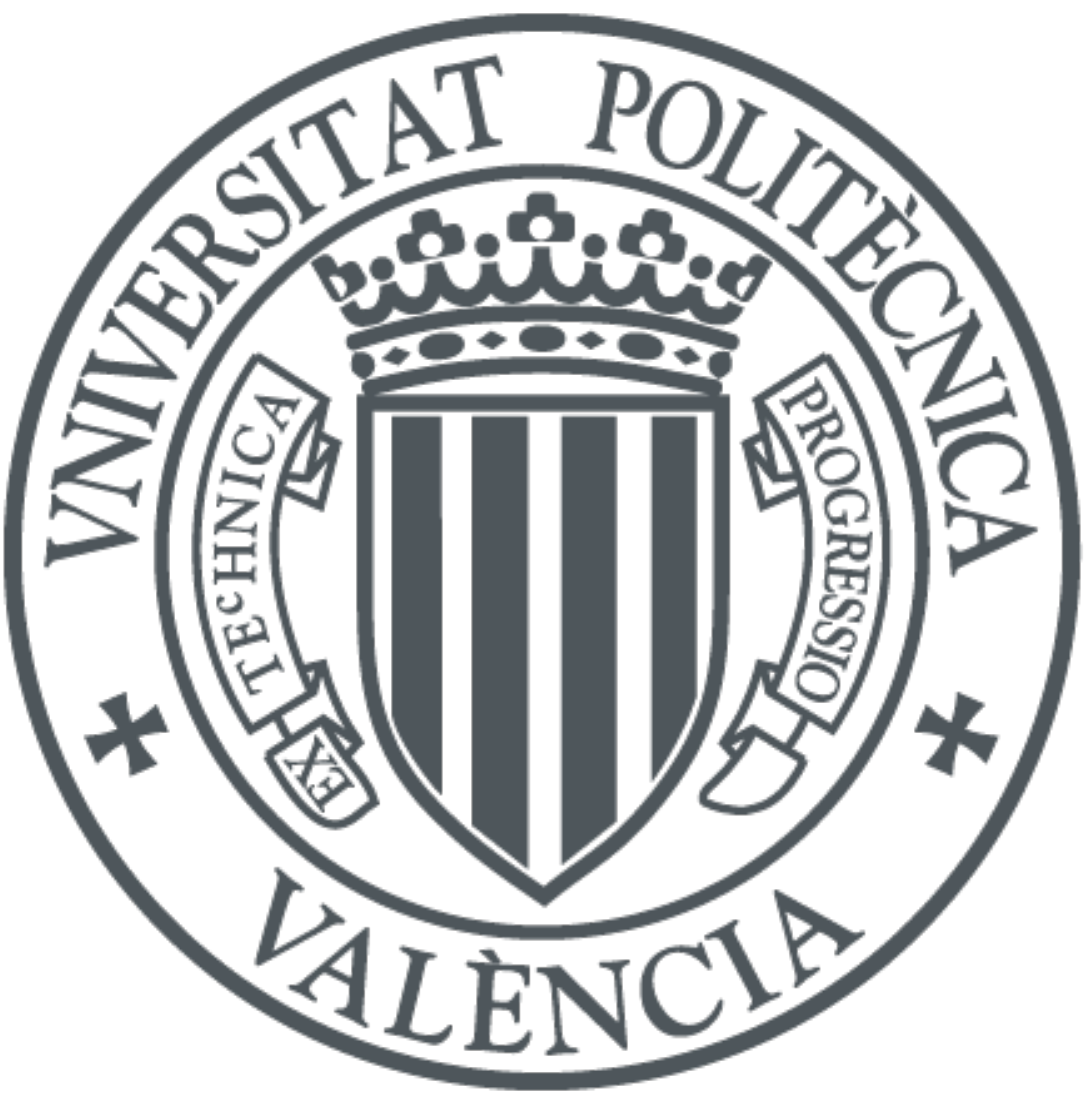

The final publication is available at

http://www.sciencedirect.com/science/article/pii/S1369800112000595

Copyright Elsevier

Additional Information 


\title{
CONTROL PARAMETERS ON THE FABRICATION OF ZnO HOLLOW NANOCOLUMNS
}

\author{
J. Cembrero*, 1), D. Busquets-Mataix*, 1), E. Rayón*, M. Pascual*, M. A. Pérez- \\ Puig*, B. Marí**
}

\author{
* Departamento de Ingeniería Mecánica y de los Materiales. Universitat Politecnica de Valencia. Camino \\ de Vera s/n ,46022 Valencia, España. \\ **Departamento de Física Aplicada. Universitat Politecnica de Valencia. Camino de Vera s/n ,46022 \\ Valencia, España. \\ ${ }^{1)}$ Corresponding authors.
}

\begin{abstract}
In the present work, the fabrication of hollow $\mathrm{ZnO}$ nanocolumns by a sequential combination of electrochemical deposition, chemical attack and regeneration is presented. Initially, $\mathrm{ZnO}$ nanocolumns were deposited in two different substrates, namely Fluor Tin Oxide and Indium Tin Oxide. In a further step, a statistical analysis on the most influencing control parameters in the dissolution stage to produce the hollow ZnO nanowires on FTO substrates was carried out. The control variables considered were electrolyte concentration, dissolution time and temperature whereas the output variable was the percentage of hollow nanocolumns obtained. The statistical analysis consisted in a two-level factorial design of experiments on three variables therefore involving a series of 8 experiments. An analysis of variance (ANOVA) on the results was also carried out. The results showed that all the control variables were significant, the most important being dissolution time.
\end{abstract}

Keywords: Hollow $\mathrm{ZnO}$ nanocolumns, two-level factorial design, ANOVA

\section{INTRODUCTION}

In present days, nanotechnology is founded not only in the development and availability of new nanostructured materials but on the control or the fabrication processes, in order to be able to scale-up the production of these materials to build devices with higher performance and repeatability.

In the field of optoelectronics, the development of nanostructured $\mathrm{ZnO}$ thin films has been an important area of research in the last years, due to their interesting inherent properties as being a wide band gap semiconductor $\left(3.7 \mathrm{eV}\right.$ at $\left.300^{\circ} \mathrm{C}\right)$ and its large free exciton binding energy $(60 \mathrm{meV})$. This makes $\mathrm{ZnO}$ to be a perfect candidate to produce light emitting and laser diodes [1-3].

$\mathrm{ZnO}$ nanostructured materials in different morphologies (thin films, nanocolumns, whiskers) have been obtained by many different deposition techniques but it was not until recently that hollow nanocolumn have been produced by means of combined electrochemical and chemical techniques [4-7]. In general, the importance of obtaining hollow nanostructures is twofold as they can increase the surface area on the one hand, and the hollow part can be functionalised, for instance, by filling with a psemiconductor to obtain a n-p junctions on the other hand. In particular, the added surface texture provided by the hollow area would increase absorption of the electromagnetic radiation by enhancing multiple reflexions.

In the present work the three-step process (growth on nanocolumns, chemical attack and regeneration) to obtain hollow $\mathrm{ZnO}$ nanocolumns on either Fluor Tin Oxide (FTO) or 
Indium Tin Oxide (ITO) substrates is described. Further, a study on the most important variables affecting the second step of hole formation is analysed by means of either two factorial design of experiments and ANOVA statistical analyses.

\section{EXPERIMENTAL PROCEDURE}

\subsection{Fabrication of the hollow $\mathrm{ZnO}$ nanocolumns.}

The procedure developed to fabricate hollow $\mathrm{ZnO}$ nanocolums consisted of three steps: (1) column formation by electrodeposition (ED), (2) chemical attack to produce the hollow structures and eventually (3) regeneration of the hollow nanocolumns again by ED. This last step was needed just in case the second step was too aggressive giving hollow nancolumns but very irregular in shape. The process is schematically illustrated in figure 1.

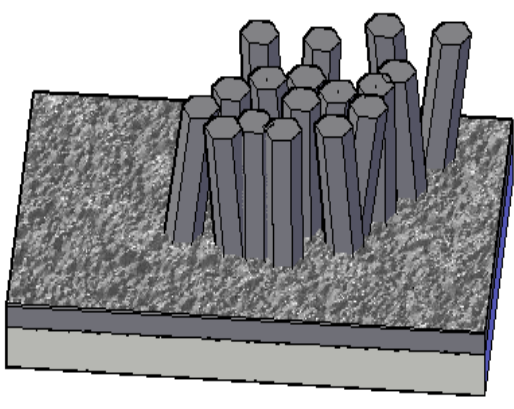

a)

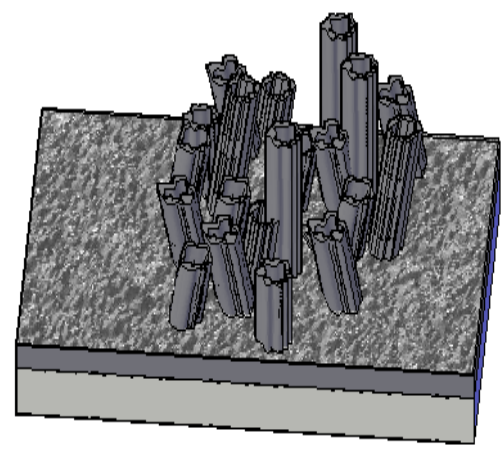

b)

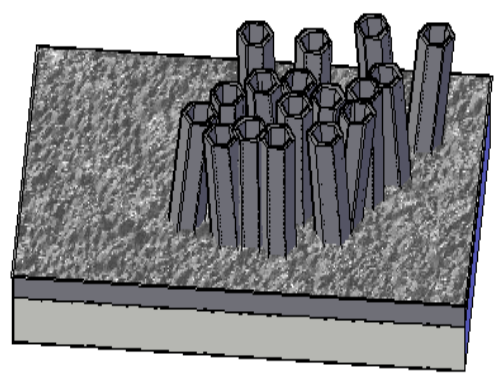

c)

Figure 1. Drawing showing the three-step process of formation of hollow nanocolumns : a) $\mathrm{ZnO}$ solid columns produced by ED; b) Hollow and irregular columns after chemical attack; c) regeneration of hollow columns by ED.

In a first instance two different substrates were utilized, (i.e. FTO and ITO on glass slid) as a way to discriminate which substrate gave the best results in terms of shape quality and to reduce the number of variables of the statistical analysis. The exposed area to the electrolyte was $1 \mathrm{~cm}^{2}$ in all cases. For the ED step(s) the electrolyte used consisted of a dissolution $5 \cdot 10^{-3} \mathrm{M}$ of $\mathrm{ZnCl}_{2}$ and $0.1 \mathrm{M}$ of $\mathrm{KCl}$ in demineralized water $(\rho>16 \mathrm{M} \Omega \mathrm{cm}$ ) as used in previous works $[9,10]$. During ED stages, the solution was saturated with $\mathrm{O}_{2}$ by continuous bubbling. Temperature was controlled with a thermal blanket and remained within $\pm 1^{\circ} \mathrm{C}$. No stirring was applied. A three-electrode cell configuration was used, being $\mathrm{KCl}$ saturated $\mathrm{Ag} / \mathrm{AgCl}$ as reference electrode and Pt wire as counter electrode. Measured $\mathrm{pH}$ in the fresh electrolyte was 6.5 whereas it decreased slightly to 6.3 at the end of the ED steps. ED cycles were carried out by using a computer controlled EG\&G potentiostat/galvanostat model 263A in potentiostatic control mode. The potential was fixed to $-0.85 \mathrm{~V}$ with respect to reference electrode and deposition time during ED step was 1800s in all cases.

Once the solid $\mathrm{ZnO}$ columns were obtained, the second step consisted in a chemical attack in $\mathrm{KCl}$ solutions, at different temperatures and times under vigorous stirring. The process is described in detail in the following subsection. 


\subsection{Two level-factorial analysis [11]}

The three aforementioned selected variables to be controlled during the second stage (i.e. chemical attack) were studied using a two-level factorial analysis. For this purpose, two different levels were set for each variable, i.e. a low level, represented by the minus sign (-) and a high level represented by the plus sign (+). The levels were selected after preliminary results gathered from previous experiences. In table 1 the set of variables and working levels used are presented. Therefore, being three the number of variables and two the levels selected for each variably, the total number of experiments to carry out in the present work results to be 8 (i.e. $2 \times 2 \times 2=2^{3}$ ).

Table 1. Set of variables and working levels analysed.

\begin{tabular}{|l|c|c|c|}
\hline \multicolumn{1}{|c|}{ Variable } & $\begin{array}{c}\text { Code } \\
\text { factor }\end{array}$ & Low level (-) & High level (+) \\
\hline Electrolyte concentration & $\mathrm{A}$ & $0.1 \mathrm{M} \mathrm{KCl}$ & $3 \mathrm{M} \mathrm{KCl}$ \\
\hline Etching time & $\mathrm{B}$ & $0.5 \mathrm{~h}$. & $3 \mathrm{~h}$. \\
\hline Temperature & $\mathrm{C}$ & $25^{\circ} \mathrm{C}$ & $60^{\circ} \mathrm{C}$ \\
\hline
\end{tabular}

The second column of table 2 summarises all the eight different combinations (design of experiment matrix). In this way, and just to give an example, sample M-3 corresponding to the following combination of variables $(-+-)$ was etched in $0.1 \mathrm{M} \mathrm{KCl}$ solution, during $3 \mathrm{~h}$ and at a temperature of $25^{\circ} \mathrm{C}$.

\subsection{Sample characterization}

The observation of the hollow $\mathrm{ZnO}$ columns was carried out with the aid of a scanning electron microscope (SEM), from JEOL, model 6300, working at acceleration voltage of $15 \mathrm{kV}$. The output variable, i.e. the percentage of hollow columns formed was calculated over a representative area in each sample of about $10 * 10$ microns.

\subsection{Statistical analysis}

The output variable (i.e. \% of hollow $\mathrm{ZnO}$ columns) was analyzed as described before by the standard Yates algorithm using STATGRAPHICS software, version 5.1. Furthermore, and using the same computer package, a more powerful analysis of variance (ANOVA) was carried out.

\section{Results and discussion.}

In order to select the best substrate for the following experiences, preliminary work using both FTO and ITO was performed. In fact, from previous experiments from the authors [12] the influence of substrate morphology (roughness) had a significant importance on the $\mathrm{ZnO}$ deposits. In the case of FTO substrate the ED potential was set to $-0.85 \mathrm{~V}$, where as in the case of ITO it was slightly increased at $-1.0 \mathrm{~V}$ just to obtain a fully coverage of the surface by $\mathrm{ZnO}$ columns. In both cases the subsequent etching step to produce the hollow columns was the same, i.e. immersion of $30 \mathrm{~min}$. in a $3 \mathrm{M}$ $\mathrm{KCl}$ solution at $65^{\circ} \mathrm{C}$. The resulting hollow $\mathrm{ZnO}$ columns are presented in figure 2 . 


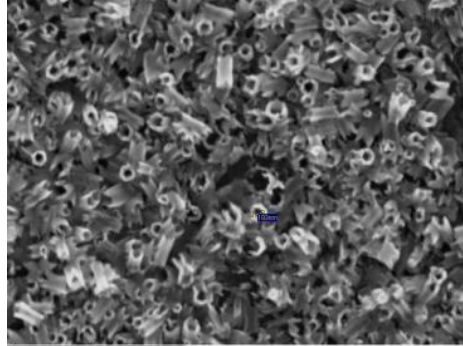

a)

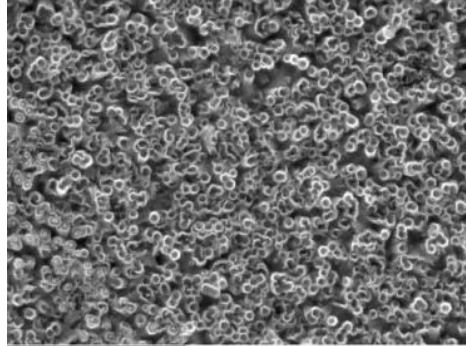

b)

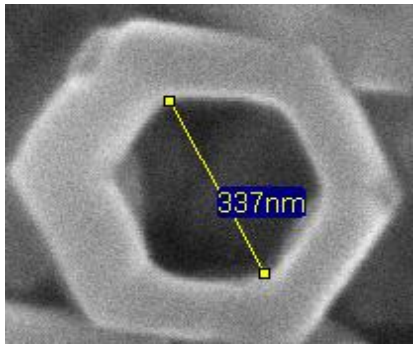

c)

Figure 2. SEM images of hollow $\mathrm{ZnO}$ nanocolumns on different substrates. a) ITO substrate. b) FTO substrate. c) Detail of a hollow column over FTO substrate.

In these images it can be observed the much better quality of the columns formed on FTO substrate compared to those formed on ITO, in terms of size, orientation and shape. In fact the columns grown on ITO are much more irregular and not quite well vertically oriented, probably a consequence of a higher roughness found in this substrate. On the contrary, the columns formed on FTO showed much homogeneous morphology, both in terms of orientation and shape. Therefore this substrate was the one selected for the following set of experiments.

On the other hand, a detail of a hollow $\mathrm{ZnO}$ column produced in this way is shown in figure $2 \mathrm{c}$ ). One can observe the regular hexagonal prismatic shape both on the walls and hole. It is important to notice that whereas the size and height of the $\mathrm{ZnO}$ columns is mainly dependent upon the parameters of the first stage (ED), the occurrence and the size of the hole will be mainly related to the parameters on the second stage. However, a theory has been proposed to explain that this preferential dissolution is due to the adsorption of $\mathrm{Cl}^{-}$ion in the top surface of the columns, i.e. (0001), being independent of the presence of defects [6].

The results for all the possible combinations in the etching stage are presented in table 2 , together with the output measured, i.e. the \% of hollow columns over the total number of columns.

The values of the output variable were analysed by using the standard Yates algorithm ordering. The results are presented in table 3 below. The mean value of hollow $\mathrm{ZnO}$ columns obtained for all the cases is $46,63 \%$. In a first instance, all the three input variables have a significant influence in the output when considered individually. From this point onwards the term "significant" will be considered in its statistical meaning. An input variable (or a combination of such) will be said to be significant when the effect of switching from the low level (-) to the high (+) level has an influence in the output variable higher than the estimated error. In the present case this error is estimated to be 3.74 percentage units in all cases. 
Table 2. Sample morphology before and after chemical etching, with \% of hollow columns.

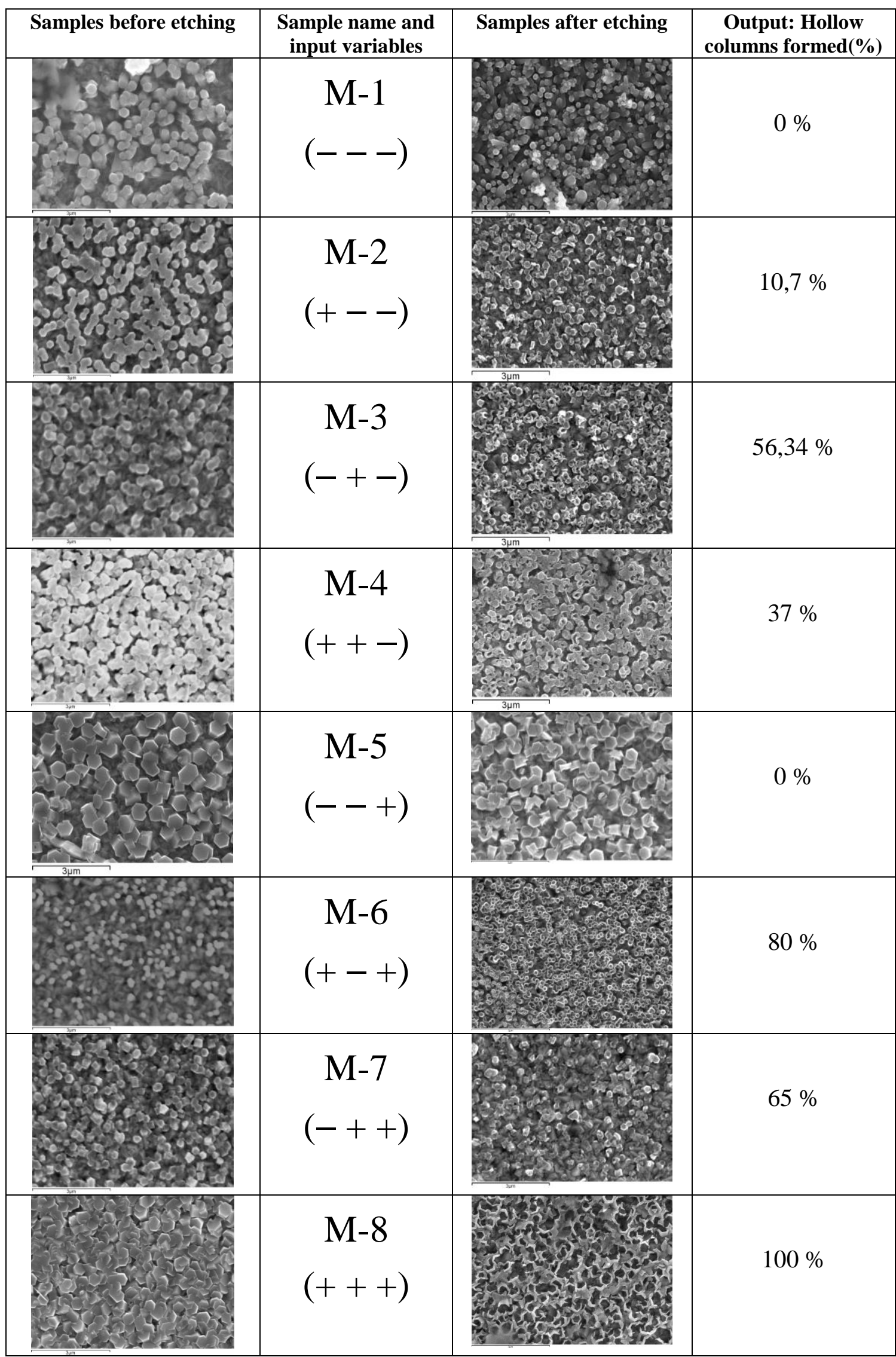


Input variable $\mathrm{A}$ ( $\mathrm{KCl}$ concentration) has a significant influence on the $\%$ of hollow $\mathrm{ZnO}$ columns obtained. In fact, the output variable is increased in more than 26 percentage units when passing from the low concentration level $(0.1 \mathrm{M})$ to the high one (3 M). The lower value concentration was established to be the lowest practical concentration limit to obtain hollow $\mathrm{ZnO}$ columns.

In a similar way, the input variable B (exposition time) is significant, being its influence the most important of all three, as the increase measured in the output variable amounts to nearly 42 units. This is clearly seen in sample M-3 in which although maintaining both the concentration and temperature at the low level, there is a meaningful formation of hollow columns.

Finally, factor $\mathrm{C}$ (electrolyte temperature) comes out to be also significant, with an increase of about 35 units from the low to the high level. With respect to this, it is important to mention that this factor is not representative when the other two are at their lower level, as one can see when comparing samples M-1 and M-5, in which there is not formation of hollow columns at all.

Although these correlations are quite straightforward and relatively easy to be worked out with simple experiments, the combined effect of some of these variables is not so clear to be ascertained and in some cases the results come out to be quite unexpected. In fact, there are two combined interactions that came out to be significant, namely the $\mathrm{AB}$ and $\mathrm{AC}$. But whereas for the latter the effect was positive, giving an increase of around 31 units in the output variable by the combination of concentration and temperature, in the former this effect was negative. In this case, when combining electrolyte concentration and time the output variable decreased in nearly 19 units. This is indicative would be enough just to consider using high level of just one of these instead of both. Finally, the BC interaction (time and temperature) resulted to be not significant because the calculated value of the interaction in output variable was measured to be lower than the error.

So the best combination resulted to be $(+-+)$ not only in terms of output but also regarding quality of the hollow $\mathrm{ZnO}$ nanocolums formed. As a matter of fact, looking in detail at the sample M-8 one can observe that although the output variable is $100 \%$ the quality of the hollow columns is not as good as in other samples, the etching procedure resulting to be too aggressive.

To this respect the procedure was developed further and a third step was introduced. This consisted of a re-deposition step by applying the same conditions as in the first step. The evolution in the morphology of the $\mathrm{ZnO}$ columns obtained is presented in figure 3. From the images, the regeneration after stage 3 is clearly apparent, although not optimum. In this image there are both bulk and hollow columns regenerated, so by an adequate control of electrodeposition time, the quantity of hollow $\mathrm{ZnO}$ columns could be maximized. In this case, the disrupted hollow columns after stage 2 are thought to become preferred nucleation sites to the re-growth of the hollow columns. Of course, this third step is not mandatory, but just to be used in case the etching procedure has been excessive. 


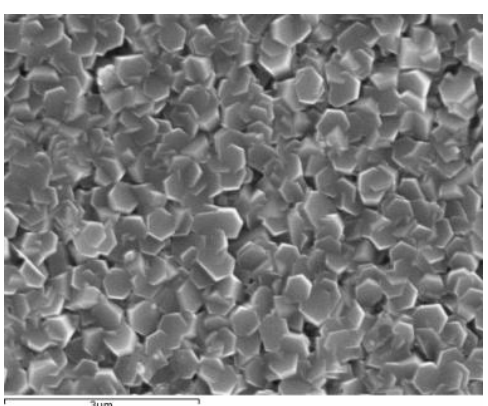

a)

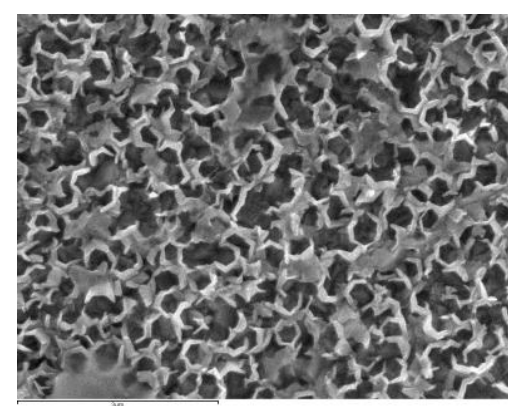

b)

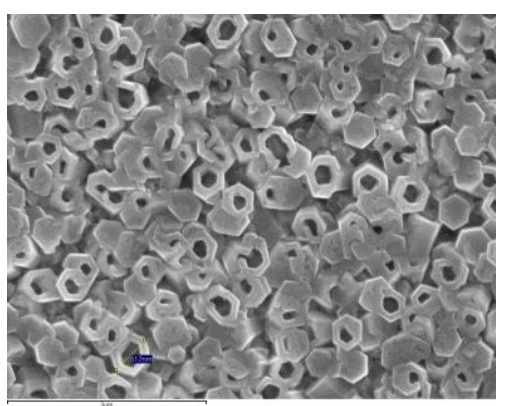

c)

Figure 3. Three step procedure for hollow column regeneration. a) Bulk ZnO columns after first step ED b) Sample after etching with all three variables (concentration, temperature and time) at the highest levels $(+++)$ c) Regeneration of hollow columns after applying the same ED conditions as in a).

Table 3. Factorial analysis results

\begin{tabular}{|l|c|c|c|}
\hline & Factors & Value & Significance \\
\hline Individual factors & $\mathrm{A}$ & $26.59+/-3.74$ & YES \\
\hline & $\mathrm{B}$ & $41.91+/-3.74$ & YES \\
\hline & $\mathrm{C}$ & $35.24+/-3.74$ & YES \\
\hline Combined factors & $\mathrm{AB}$ & $-18.76+/-3.74$ & YES \\
\hline & $\mathrm{AC}$ & $30.91+/-3.74$ & YES \\
\hline & $\mathrm{BC}$ & $0.59+/-3.74$ & NO \\
\hline Mean & - & $43.63+/-1.87$ & - \\
\hline
\end{tabular}

Continuing with the statistical study of the influence of the input variables, a more powerful analysis is to carry out an analysis of variance. In this analysis the influence of each variable alone or in combination with the others with respect to the output mean value and variance is evaluated. Usually the input variables (or a combination of those) are considered to be significant when the value of the parameter P-value is below 0.05 (meaning that the respective input variable is significant with a probability higher than the 95\%). To this respect, none of the factors would reach this level. However one must always bear in mind that the statistical assumptions made for this kind of analysis not always hold, we ranged the level of significance of the different input variables in relation to how close are to 0.05 .

Table 4. Analysis of variance results (ANOVA)

\begin{tabular}{|l|c|c|c|c|c|}
\hline Factors & $\begin{array}{c}\text { Sum of } \\
\text { squares }\end{array}$ & Mean square & F-Ratio & P-Value & Significance \\
\hline A & 1414.06 & 1414.06 & 50.55 & 0.0890 & Medium \\
\hline B & 3512.9 & 3512.9 & 125.57 & $\mathbf{0 . 0 5 6 0}$ & High \\
\hline C & 2483.72 & 2483.72 & 88.78 & $\mathbf{0 . 0 6 7 3}$ & High \\
\hline AB & 703.875 & 703.875 & 25.16 & 0.1253 & Low \\
\hline AC & 1910.86 & 1910.86 & 68.31 & 0.0767 & High \\
\hline BC & 0.6962 & 0.6962 & 0.02 & 0.9004 & None \\
\hline Error & 27.9752 & 27.9752 & - & - & \\
\hline Total & 10054.1 & & & & \\
\hline
\end{tabular}

The interpretation of results gives no variable significant with a probability higher than that specified. However, all three variables taken individually and the combination of 
concentration and temperature reach the maximum values of probability, result which is in agreement with the previous results.

\section{CONCLUSIONS}

The formation of hollow $\mathrm{ZnO}$ columns has been obtained by a combined process of electrodeposition and chemical etching. This second step is accomplished with $\mathrm{KCl}$ solutions using concentrations higher than $0.1 \mathrm{M}$.

All three variables controlling the second step (electrolyte concentration, etching time and temperature) are significant in the formation of hollow $\mathrm{ZnO}$ columns.

There is a combined positive effect of $\mathrm{KCl}$ concentration and temperature, but this factor is not determinative alone.

If the etching procedure is too aggressive, the quasi complete dissolution of the $\mathrm{ZnO}$ deposit may occur. Nevertheless, by applying another electrodeposition step the hollow $\mathrm{ZnO}$ nanocolumns are regenerated.

\section{Acknoledgements}

This work was supported by Spanish Government through MCINN grant MAT200914625-C03-03 and Generalitat Valenciana programme PROMETEO/2009/063. Technical support given to the authors by the Servicio de Microscopia at the Universitat Politècnica de València (Spain) is greatly acknowledged. 


\section{REFERENCES}

1. B. Mari, J. Cembrero, M. Mollar, M. Tortosa, Phys. Status Solidi C 5 [2] (2008) 555

2. V. Donderis, M.A. Hernandez-Fenollosa, L. C. Damonte, B. Marí, J. Cembrero, Superlattices and Microstructures 42 (2007) 461

3. B. Mari, J. Cembrero, F.J. Manjon; M. Mollar, R. Gómez, Phys. Status Solidi A 202 (2005) 1602

4. L. Vayssiers, K. Keis, A. Hagfeldt, S.-E. Lindquist, Chem. Mater. 13 [2] (2001) 233

5. Y. Tang, L. Luo, Z. Chen, Y. Jiang, B. Li, Z. Jia, L. Xu, Electrochemistry Commun. 9 (2007) 289

6. J. Elias, R. Tena-Zaera, G.-Y. Wang, C. Lévy- Clément, Chem. Mater. 20 (2008) 6633

7. C. Yan, J. Liu, F. Liu, J. Wu, K. Gao, D. Xue, Nanoscale Res Lett. 3 (2008) 473

8. M. Izaki, T. Omi, Appl. Phys. Lett. 68 (1996) 2439

9. J. Cembrero, M. Perales, M. Mollar, B. Marí, Bol. Soc. Esp. Ceram. Vidr. 42[6] (2003) 379.

10. R. Könenkamp, K. Boedecker, M.C. Lux-Steiner, Appl. Phys. Lett. 77 (2000) 2575

11. J.O.M. Bockris, A.K.M. Reddy, Modern Electrochemistry, Plenum Press, 1998.

12 J. Cembrero, D. Busquets-Mataix, Thin Solid Films 517 (2009) 2859 